\title{
Composing through Interaction: a framework for collaborative music composition based on human interaction on public spaces
}

\author{
Mauro Amazonas $^{1}$, Thais Castro ${ }^{1}$, Rosiane de Freitas $^{1}$, Bruno Gadelha ${ }^{1}$ \\ ${ }^{1}$ Universidade Federal do Amazonas \\ Av. General Rodrigo Octávio, 6200 - 69080-900 Manaus, AM
}

[mauro.jr, thais, rosiane, bruno] @icomp.ufam.edu.br public [2]. facilities with technology to create an interactive environment for people. To foster public interaction in these spaces, public art in a digital context emerges as an alternative given that this type of art emphasizes participant subjectivity, participation, bi-directionally, and feedback. Digital public artworks differently from traditional public art, that is, the artist does not entirely control the content, and the power of creativity is in the hands of the public. In this process, interaction requires that artists give up creative power and objects to be enjoyed freely by the

Music and Sounds are forms of artistic expression that is often realized in public spaces. Sound Art or Sonic Art (SA) encompasses very diverse types of creation based on the exploration of sound ("literal or implicit") as the main element, whether in combination with more traditional arts such as painting and sculpture or with digital and interactive media. It is a mutant definition, as it includes more and more emerging genres, in addition to sculptures and sound installations, electroacoustic music, acoustic, algorithmic, computer music, and noise [3].

Mobile devices are available computational devices that are already disseminated and can be explored to provide human-human, human-environment, and humanenvironment-human interaction [4]. They bring mobility, processing power, connectivity, and relatively low cost. When analyzing their multiple functionalities, it is realized that these devices can be considered of general-purpose and have the capacity to mitigate the costs for simple solutions like controlling the reproduction of a player or even more complex like a collaborative music composition through an Application like Trackd [5].

This paper presents research that aims to explore SA as a public art installation. In this installation, people can interact with the environment through sounds using mobile devices resulting in a collaborative electroacoustic music composition approach. The main characteristic of this approach is its unpredictability that is achieved by the free interaction of the users in the public space. This issue gives us the random component of the strategy and the resulting music goes towards John Cage's random style [6], but unlike him, we don't have a single composer but multiple composers. This fits the concept of public art in the sense that we don't have control over the user's interaction in the environment, and the resulting collaborative music is always unique and unpredictable. The resulting composition is a piece of electroacoustic music 
that, according to [7], this kind of music is composed of previously recorded sounds, which are later treated in a computer and worked musically to build the final product (work).

The remainder of the paper is organized as follows. Section 2 presents some concepts about the field of study of sonic interaction design and its application in this work. Section 3 presents examples of applications that make use of technology to enable collaborative music creation. Section 4 explains some concepts and possibilities in the exploration of the spatiality of sound for the artistic field. Section 5 presents the materials and methods used in the development of this research. Section 6 presents the Compomus app and its versions used during this study. Section 7 explains the case study carried out to evaluate the acceptance of the proposed technology. Finally, the conclusions of the study are presented in Section 8.

\section{Sonic Interaction Design}

The way to interact and how to develop the sound design of products or artifacts are studied by Sonic Interaction Design (SID), an emerging field of study that is situated at the intersection of auditory display, interaction design, ubiquitous computing, and interactive arts. SID can be used to describe practice and research in any of the various functions that sound may play in the cycle of interaction between users, artifacts, services, or environments [8].

A classic example of the SID application was the first iPod model, which used a mechanical scroll wheel as the input device: a rotating wheel to allow scrolling between menu items. The element that replaced the mechanical wheel used on iPods is the clicker: a click sound that provides feedback for movement between menu items. This feature gives a tactile feel to the click wheel (a pseudo-haptic illusion), somewhat similar to the turntable on old phones, making scrolling more expressive and more informative. The click sound is the only sound produced by the iPod outside of the headphones and is generated through a small piezoelectric speaker inside the device [9].

New forms of interaction with sound have been presented using technologies, playful, artistic, and creative experiences that are provided through the relationship of art to science and technology. Based heavily on SID concepts, the authors in [10] developed interactive interfaces that use ReactVision software to view tags and control sound. From this technology, several concepts of the study have experimented in different scenarios with individual musical performances, group and collaborative applied in schools and art exhibitions.

In this work the SID is applied as follows: the user assumes one of the sounds available in the application used as his identity in the interaction space, what happens is the "sonification" of the participant. This personification of the sound occurs in both the PlayStop version and the JoyStick version. The interaction of users with the environment using the PlayStop version takes place through the movement, which is captured and processed by the smartphone sensors and sent to the audio server. The now "sonified" user has their sound played in the speakers and can interact with other users while inside the interaction space. In the JoyStick version, the user has control of the reproduction of their sound as well as their spatial location to interact with other sounds and the environment.

\section{Creating Collaborative Music with Emerging Technologies}

The human being is very creative and always looks for different ways of making music, whether mixing rhythms, languages or even using different types of instruments. Music composition is a naturally collaborative process, and new technologies and internet infrastructure improvements enable this collaboration in music production and composition to be performed by countless people in different physical locations.

However, while technological advances allow such exploits, technology seems to be individualizing the human being even in activities that were previously practiced together. An example would be the production of a song, in which it was only a short time ago that the artists traveled to another country to produce their album. Today this is a thing of the past, using software like the aforementioned Pro Tools Collaboration [11], artists from different parts of the globe can work on a project together without leaving home. While breaking borders and allowing interaction with people in multiple places, technology has also kept us from personal relationships in the same environment, today we can do a lot without leaving home and interact less and less with each other in "old" style [12].

Against the current technological trends, the Compomus focuses on the interaction and collaboration of the participants in the same place spontaneously and encouraging communication and organization by the participants themselves. The environment allows users to be autonomous and independent in creating music using their smartphones. The technology, in this case, functions as a means for participants to more easily interact and observe the impact of their actions on the environment.

\section{Real-Time Sound Spatialization}

The human being can determine the location of a given sound, due to the hunting ability developed by his ancestors. This ability works by employing auditory indications that are perceived by the auditory system. According to Lord Rayleigh [13], the interaural time difference (DTI) and the interaural intensity difference (DII) are the most commonly used indications. The DTI indicates the difference in time that the sound wave takes to reach each ear and the DII the difference in intensity. It is understood that the auditory system, based on these indications and more specific ones (such as the order of arrival of the waves and the spectrum), considering a complex sound, 
determine the position (direction and distance) of the source through a voting system [14].

In acoustic music performance, there are no musicians positioned on a stage, and the play is performed in an arrangement of loudspeakers positioned in the presentation place and around the listeners. In most presentations, it is the composer who controls a sound table placed in the center of the presentation location, processing and directing the sound in real-time to the speakers and thus shaping the space [15]. In this way, there is a mobility of sound around the audience, creating an exciting surrounding effect. The audience usually feels that they are immersed in sounds. The artist who controls the direction and mobility of sounds in space through loudspeakers creates the sound spatialization effect (sound diffusion or electroacoustic diffusion).

\section{Methodology}

For this project, a literature review was carried out to know the state of the art, tools, and technologies that could be used. In this search, we have observed several tools like OSC protocol, Pure Data, and approaches such as sound spatialization and Sonic Interaction Design (SID). Based on these observations, Pure Data, SID principles, and sound spatialization were incorporated into the project, thus expanding the theoretical, technological and artistic possibilities of this work. In the Pure Data platform was developed a framework for the reproduction and sound spatialization on the Open AUDIENCE architecture for an immersive auralization to provide a differentiated experience for the user [16]. The Ambisonics auralization technique was chosen for use in this work because of its easy implementation, low computational cost, flexible speaker configuration, capable of supporting multiple people simultaneously and good directionality of virtual sound sources. For the mobile side, the mobile development platform chosen was Android as the most used platform in the world [17] and for its ease and freedom of development.

To achieve the intended results in this study, two versions (with different goals) of the application Compomus for Android were implemented. The first, PlayStop version, detects the user's presence in space and plays their chosen sound without any further intervention. Playback terminates when the App detects that the user has left the space set. The second, JoyStick version, allows the user beyond the control of sound reproduction, control the spatial location of the same. For this, a case study was carried out with the volunteer students using the two versions created in a space defined within the University. This study generated five musical compositions and their results can be checked in [18].

The material used to perform a musical "performance" are devices easily found in our everyday life and at low cost such as a standard internet router, a generic USB sound card with 5.1 channels, cables, four boxes portable sound and a notebook. These equipment are the requirements for a quadraphonic musical composition, in which it is possible to explore the spatiality of the sound in this case. There is also the possibility of making use of only two speakers in stereo mode. Further details of each of these components can be observed in the following sections.

\section{Compomus}

This research originated from the demand for a partnership between the Faculty of Arts and the Institute of the Computing of the Federal University of Amazonas. The idea of this partnership was to join the Arts (especially music) with Technology, addressing the problem of the composition of music with the use of emerging technologies.

The scope of this work is in electroacoustic music (more precisely in live electronics). The interaction of users and their collaboration through their smartphones become an integral part of the work as a source of originality for the composition of musical works intended to be performed in real-time in public spaces. With the participation of an indefinite number of people, the work appears in the contribution of each person with its sound. Some participants can organize the composition or not, also allowing their inter-communication. All this interaction with the system is processed, reproduced, and recorded in real-time.

The main idea of the proposed system is to allow users to cooperate in composing a sound through their free interaction with other users, and with the sound, they choose to represent them. The composition space can be a room or an open public space with a limited area. Loudspeakers are needed to reproduce the sounds of the users who are within this space. The dynamics of system use is as follows: once a user is within the defined area, their sound is played in a loop, if you move away from the assigned space, the system interrupts the playback of your sound. What defines whether or not the sound will be reproduced is the user's distance from the center of the interaction space. The speakers play a critical role in the system as they are responsible for audio feedback to the users. Users entering and leaving the interaction space turn the sound on and off on the speakers.

As previously mentioned, the App Compomus was developed on the Android platform and functions as a controller for an audio server that processed all the commands and sent by the App executing the sounds. This audio server was developed in Pure Data and uses as sound spatialization engine the Open Audience Architecture and receives commands through the network. A webserver was also designed to control and register users. To support the scenario described above, we have developed a diagram that demonstrates the dynamics of the environment represented in Figure 1, which comprises: A server with a dual function, webserver, and audio server. Four amplified speakers connected to the audio server for feedback in the interaction space. A router, which functions as an access point and allows the connection between the application and server. In the PlayStop version, the radius set is calculated by the App that can determine whether or not 
the user is in the interaction space. When the application detects that it is within the interaction space, the sound chosen by a user is played in the speakers.

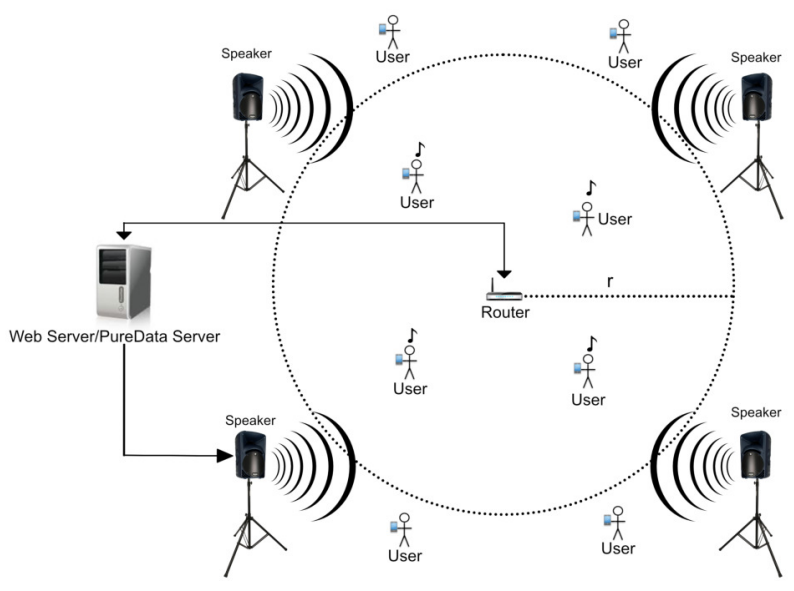

Figure 1: System Function Diagram.

When the version used is the JoyStick version, the defined radius is scorned and from anywhere within reach of the wireless network, it is possible to reproduce the chosen sound besides also be able to direct it to the soundbox of your choice. More details of the two versions are presented in the following subsections.

\subsection{Compomus PlayStop}

The App Compomus PlayStop is the implementation of the idea initially proposed in the project. However, during the researches, the possibility of exploring the spatial sound also appeared, being necessary to separate the two solutions so that these were evaluated separately. The PlayStop version works relatively clear, in Figure 2 it is possible to check the screens of use of the App where it is first necessary to make a user registration and choose a sound. Just as in the JoyStick version, there are 50 sounds of the electronic genre available for free on the LANDR website [19].

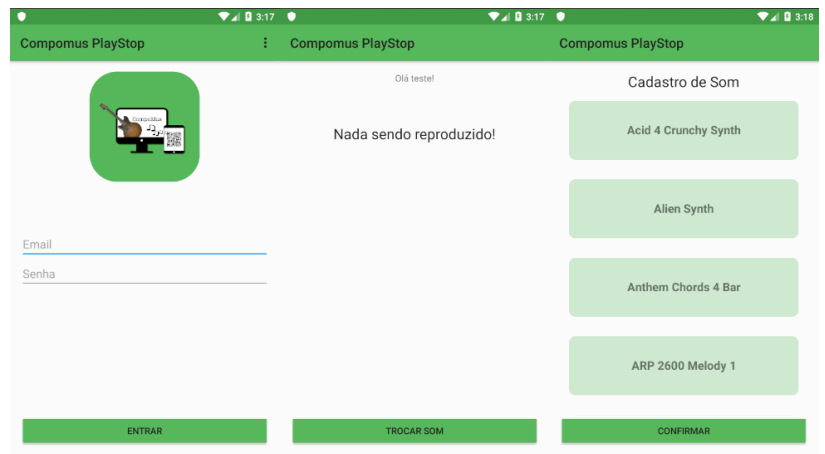

Figure 2: Main screens of the App in the PlayStop version, available only in Brazilian Portuguese.

The second screen is the main screen of the App in which the feedbacks are presented to the user, the "Nothing playing" message is displayed when the user is not inside the interaction space and the "Playing your sound" is displayed when the app detects that the user is within the defined area. At any moment, the participant can change its sound. For this, there is a button on the main screen that allows such action. The third screen has the list with the available sounds.

In this version, the participant of the composition needs to move, leave the space defined to stop the reproduction, which is intended to stimulate the movement between users. To evaluate this version was carried out a case study in which the users could test the application that was made available via the application store of the Android system.

\subsection{Compomus Joystick}

The Compomus JoyStick is the version of the App that explores sound localization as an artistic element, in which case the user will have a control to move the sound in an environment with scattered speakers. The JoyStick version has differences of functionality concerning the PlayStop version since it does not require the user to move through the space Figure 3.

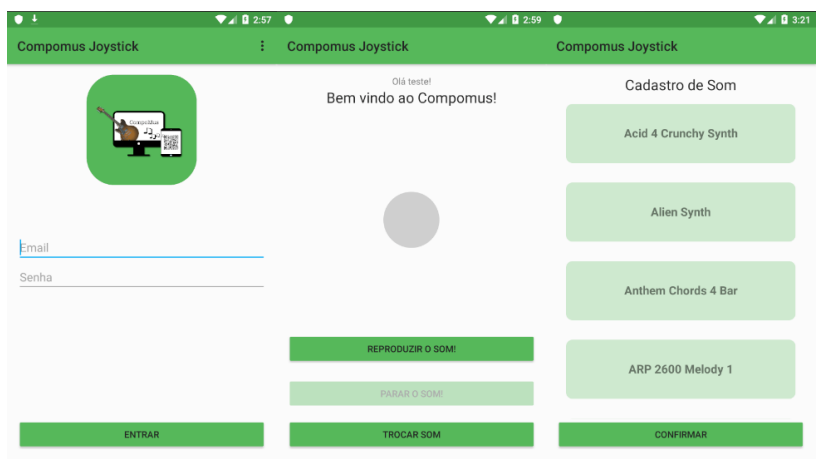

Figure 3: Main screens of the App in the JoyStick version, available only in Brazilian Portuguese.

The dynamics of using the App in this version is very similar to the PlayStop version, the initial screen and register works in the same way as the previous version, as well as in the selection screen of a new sound. The difference is in the main screen (central screen), where a button is available to play and one to stop the sound reproduction and a directional joystick that controls the movement of the sound. There is also the sound switching button that allows the user to change the sound at any time.

\section{Case study}

A case study was carried out to study musical composition in a scenario in which there is no "central actor", that is, without any particular organization in which one depends exclusively on the collaboration and interaction of the people present in a given environment. This study was carried out in an experimental setting, in an environment simulating an installation in a public space. This methodology was used based on Yin's claim [20] that the case study is the most appropriate methodology to use in research where the main questions are "how?" 
Or "why?". The author also refers to the case study as an indicated methodology for social studies. Therefore one of the topics addressed in this work.

Also according to the literature [20], as steps for conducting case studies, there are: the Plan, which consists in deciding the methodology that will be used for the research; o Design or Project, where the units of analysis should be defined and the probable case studies; a Preparation consisting of one or more pilot case studies; the collection, where the data generated by the pilot study are extracted, and finally the Analysis stage, which consists of an analysis of the collected data. If collection is not sufficient, one may return to the preparation stage for further pilot case studies, or even if the generated data is not desirable, it is necessary to return to the design stage.

Plan: the context that this work is inserted is that of the collaborative sound composition, placing the user as a composer and interpreter of a sound to be built by the individuals themselves collaboratively even if they do not have previous knowledge about musical composition when doing use of the proposed applications.

Design: the aim is to identify improvement points and evaluate users' acceptance of the proposed technology. If the users felt composing a sound even without harmony or synchronism, it was observed that they were collaborating for a musical composition as a whole.

The research involves data collection in the interaction space created within the University. The technological platform developed is new and, as there were no references to assess its viability, it was decided to conduct two pilot case studies first. Data collection was performed by observing the interaction, post-test questionnaires printed and answered by all pilot study participants after each session. For the analysis of the collected data, each pilot case study had some of its most relevant characteristics observed, and its data were collected and discussed in detail in the next section.

To evaluate the results obtained in the analysis and to find out if the technology would be well accepted by the users, the Technology Acceptance Model (TAM) model was used. The TAM model was designed to understand the causal relationship between external variables of user acceptance and actual use of the computer, seeking to understand the behavior of these users through the knowledge and ease of use perceived by them [21]. According to the guidelines of the TAM model, five hypotheses were elaborated that can be checked next. These hypotheses are validated through a questionnaire applied after the use of the technology.

- H1 - Perceived usefulness is affected when there is no collaboration between participants.

- H2 - Intention of Use is affected by cultural influences.

- H3 - Perceived Usability Facilitates engagement with technology.

- H4 - Perceived Usability and Ease of Use provide a positive experience with technology even with- out knowledge of musical concepts.

- H5 - The ability with technological devices and their resources improves personal performance in the use of technology.

A questionnaire with 30 questions using the Likert [22] scale was developed to validate the questions the hypotheses elaborated. The Likert range has five levels that are defined to capture the points of choice of the users interviewed. In this case, the points of choice are:

1. Strongly disagree

2. Disagree

3. Neutral

4. Agree

5. Strongly agree

The study was conducted within the university premises with the participation of 47 volunteer students who used both versions of App Compomus Joystick and PlayStop. These studies are best described in the following subsections. The two studies were conducted on the same day, and students were divided into groups for physical space issues.

\subsection{PlayStop Pilot Study}

- Preparation: A space of approximately 36 square meters was reserved for our studies as shown in Figure 1. Four portable speakers were plugged through cables to the USB sound card that was used to reproduce the processed sounds in the notebook. This equipment was used as an audio and web server. We also used a standard router, located right in the center of the defined space, which served as the access point used in the study. As this version does not explore the spatiality of the sound, in this study all the sounds were reproduced equally by the speakers.

- Execution: participants were first asked to download the App from the app store. Then they were asked to connect the network made available by the system router to register and use the space. It was explained to the participants the operation of the App as well as the dynamics of the process of the interaction space Figure 4.

Participants were asked to feel free to interact as they wished. User interactions have been recorded in audio and video recording. However, only images can be checked on the page created for the demonstration of results in photos and audio [18]. Users could use the app in the environment for five minutes in each round of the study; at that time, they were free to interact or not.

\subsection{JoyStick Pilot Study}

- Preparation: to perform this study after the use of the PlayStop version the participants were invited to use the JoyStick version of the Compomus in the same space and to use the same structure of the previous study Figure 5. 


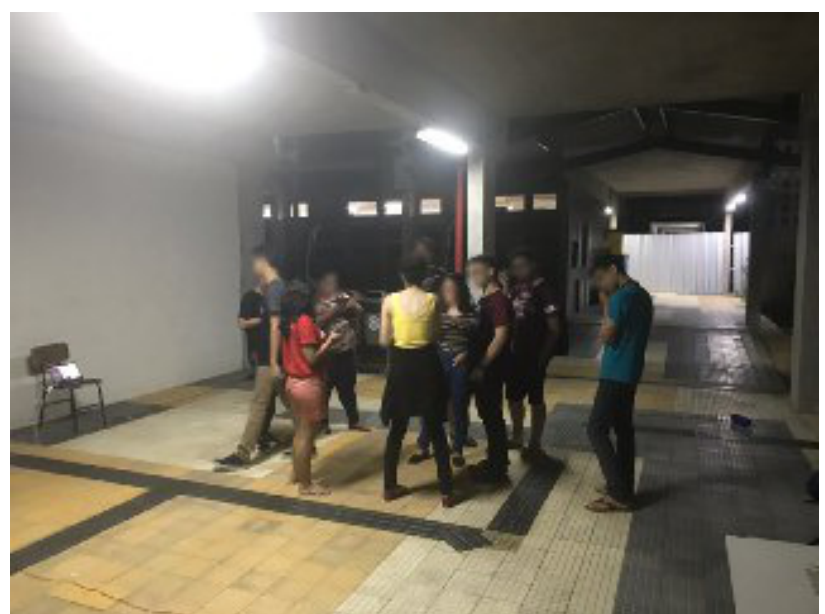

Figure 4: Participants during the study making use of the APP defining composition strategies among themselves.

- Execution: participants were asked to download the App in the JoyStick version, in this case, a new registration was no longer necessary since both use the same database. was asked to download the App in the version JoyStick, in this case, it was no longer necessary a new registration since both use the same database. As in the previous study, we explained to the participants the dynamics of using the App and its operation. The time available to the participants of this study was five minutes in which it was suggested that they could use the App the way they wanted. An example of using this version can also be checked on the page created in http://compomus. wixsite.com/compomus [18].

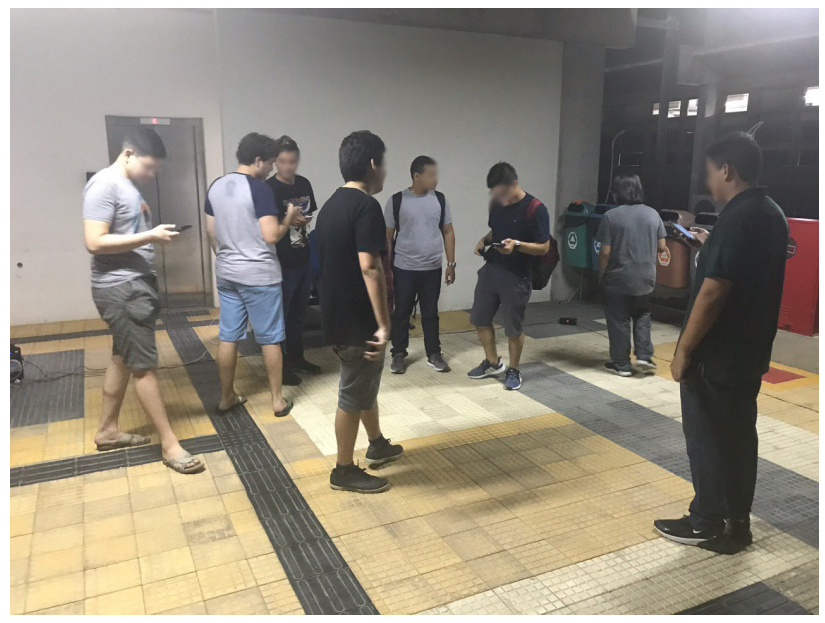

Figure 5: Participants are making use of the App and verifying the movement of the sound.

After each round of use of the Applications, respondents were asked to answer the questionnaire prepared according to their vision and the feelings experienced during the study, were also asked to be as sincere as possible in their answers.

\subsection{Result analysis}

At this stage, the predetermined hypotheses were verified at the beginning of this section, relating them to the answers obtained in the questionnaire applied to the study participants. This analysis consisted of in-loco observations by the researchers and the documentation by audio and video recordings as well as the application of a posttest user experience questionnaire to record participants' impressions. Two graphs Figure 6 and Figure 7 show the distribution of study participant responses for each version. A more detailed analysis can be given below.

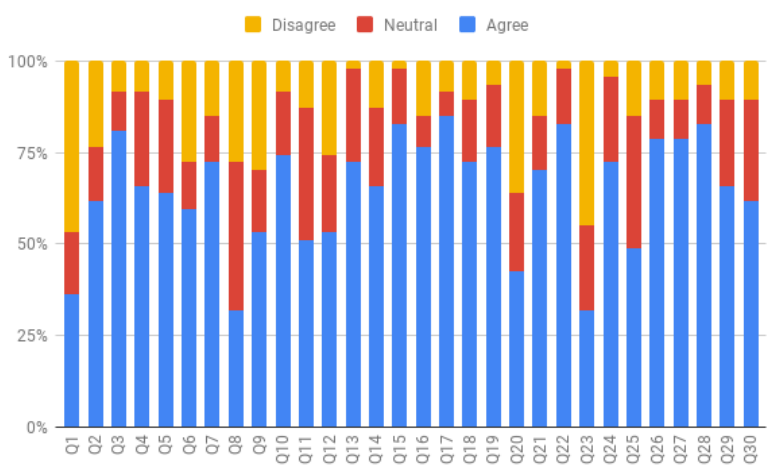

Figure 6: Average answers to the 30 questions in the JoyStick Version questionnaire.

H1: Considering questions 1 to 7, this hypothesis was confirmed, according to the figures about $53.19 \%$ of participants who used the PlayStop version pointed out in item 1 that there was a spontaneous organization by the group. On the other hand, $36.17 \%$ of the participants stated that there was no organization when they used the JoyStick version, $17.02 \%$ were undecided. In answering question 2, in which $68.09 \%$ of participants noted that the sound is most interesting when several people reproduce their sounds together in the PlayStop version. Users of the JoyStick version at about $61.7 \%$ also agree. ${ }^{1}$ In response to question $4,65.96 \%$ of the participants agreed that there was no type of prior organization for the generation generated in the use of the JoyStick version. This number was $76.60 \%$ among users who made use of the PlayStop version. When asked if they felt they contributed to a composition in question $7,70.21 \%$ of the participants agreed with the statement and felt responsible for the work generated in the PlayStop version. Already using the JoyStick version, users felt much more active in the participant part of the composition about $72.34 \%$ of users.

H2: Considering questions 8 to 13 , this hypothesis is partially confirmed according to the numbers obtained in the answers to question 11. In this question, $51.06 \%$ of participants who used the JoyStick version stated that they have an affinity with electronic music since the sounds used are of this style. Already $59.57 \%$ of participants who used the PlayStop version also agreed to have a good relationship for style. Identification with

\footnotetext{
${ }^{1}$ The results presented are the sum of the answers I agree to and strongly agree, as well as strongly disagree and strongly disagree.
} 
the style of electronic music present in the App sounds caused an unexpected positive result among participants in their responses. This result does not fully confirm the hypothesis since a larger number of users with no affinity with the electronic music used for this study were expected. In answering question $8,46.81 \%$ of the participants who used the PlayStop version were undecided when asked if the people in their circle of friends like the same musical styles. This number was $40.43 \%$ between JoyStick version users. In answering question 10, about $80.85 \%$ of participants who made use of the PlayStop version like different/alternative ways of making music. Already $74.47 \%$ of users who made use of the JoyStick version also claim to like different/alternative ways of making music. Identification with the style of electronic music present in the App sounds caused an unexpected positive result among participants in their responses. This result does not fully confirm the hypothesis since a larger number of users with no affinity with the electronic music used for this study were expected.

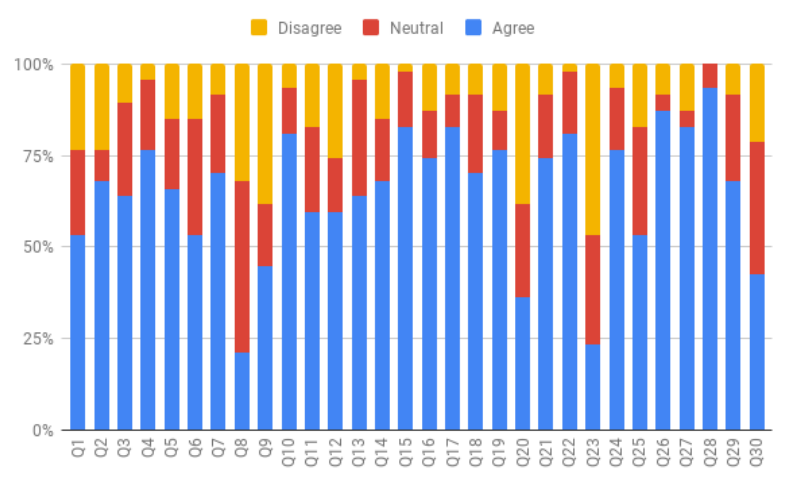

Figure 7: Average answers to the 30 questions in the PlayStop Version questionnaire.

H3: Considering questions 14 to 19 , this hypothesis is confirmed. According to the figures found in the questionnaires when analyzing the answers to question 14 , about $68.09 \%$ of users that were used the PlayStop version stated that they did not have experience with musical composition, but they not find difficulties to make music in this case. $65.96 \%$ of users who made use of the JoyStick version also agree that it was easy to make music even without experience in musical composition. In response to question $15,82.98 \%$ of users who made use of the PlayStop version stated that the simplicity of the App made their experience with technology more accessible, this number was $82,98 \%$ between JoyStick users. In question $18,70.21 \%$ of users who made use of the PlayStop version confirmed that they managed to dominate without any problems the dynamics of the use of the App. In the JoyStick version, this number was $72.34 \%$.

H4: Considering questions 20 to 25 , this hypothesis is confirmed according to the verified answers. In response to question $21,70.21 \%$ of users of the JoyStick version stated that random sounds could indeed result in a single composition, among users of the PlayStop version that number was $74.47 \%$. In question $22,82.98 \%$ of
JoyStick users concluded that this is a musical expression type. Among the users of the PlayStop version, this number was $80.85 \%$. In response to question $24,72.34 \%$ of users of the JoyStick version have confirmed they have enjoyed creating music from different sounds. $76.60 \%$ users of the PlayStop version also confirmed that they enjoyed creating music in this way.

H5: Considering questions 26 to 30, this hypothesis was confirmed according to the analysis of the answers collected. In response to question $26,78.72 \%$ of users of the JoyStick version confirmed to use more than one electronic device daily. This number was $87.23 \%$ of the PlayStop version users. In response to question $28,82.98 \%$ of participants who used the JoyStick version claimed to have great skill in the handling of electronic devices. Already $93.62 \%$ of users who tested the PlayStop version claim to have great skills when it comes to electronic devices. In question 29, $65.96 \%$ of users who used the JoyStick version claimed to control the sound in a proposed way without much trouble. This number among users of the PlayStop version was $68.09 \%$.

Overall, the results achieved in terms of technology acceptance are positive. The hypotheses are considered confirmed when they reach $50 \%$ or more in the average of answers that agree with the applied questions Figures 8 and 9.

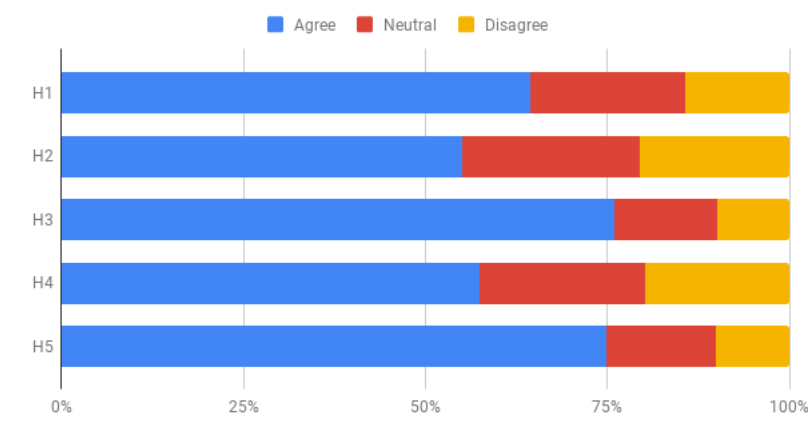

Figure 8: Results from PlayStop TAM questionnaire (average by hypothesis).

The interaction with sound through mobile technologies is an artifact with the potential to be explored in the field of public art. The interaction of the participants with the spatialization of sound is also another factor to be investigated since it gives new creative possibilities to the composers.

This study evaluated the potentialities and alternatives that can best be employed in the next version based on what was analyzed through the applied questionnaires. The compositions generated from the interaction of the participants can be considered unique and irreproducible since they are the factor that inserts the randomness and unpredictability in work. This leads us to a random collaborative music composition using a methodology different from that used by John Cage. In this scenario, the agent of change is the very interaction of the participants with the sound through their smartphones (“instruments”) 


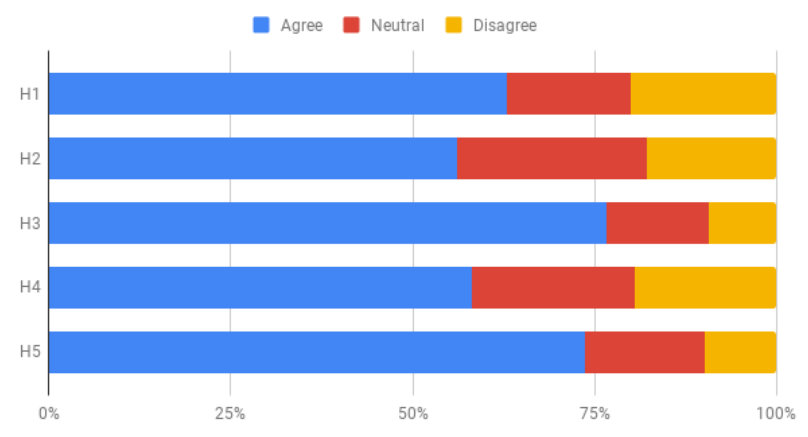

Figure 9: Results from JoyStick TAM questionnaire (average by hypothesis)

in space either by reproducing the sound or by working their spatiality.

\section{Concluding Remarks}

We presented the Compomus app, a framework for collaborative music composition for immersive interaction with sound. We defined a case study with two versions of the Compomus: JoyStick and PlayStop.

The subjects participating in the study interacted with the sound in a university place simulating a quadrangular public space. By their mobile devices (smartphones), participants adopt the JoyStick version, that detects when the user is present in the environment, to play their sound. In this version, the user besides the control of the sound reproduction also has the power of the sound spatialization and can direct its sound in any direction. At the end of the interactions, the users answered a questionnaire based on five hypotheses that aimed to evaluate the acceptance of the technology. Thus, four of the five assumptions were confirmed, and one of them was partially established, showing empirically in the data a good acceptance by the users. As a result, ten sound compositions were generated. Five compositions were obtained through the PlayStop version and are available on the stereo system. The other five compositions were obtained through the JoyStick version in the quadraphonic system.

We make available on a website [18] to participants and evaluators of this study could verify the results of the interactions for the two Compomus app versions proposed.

\section{References}

[1] Vicky Cattell, Nick Dines, Wil Gesler, and Sarah Curtis. Mingling, observing, and lingering: Everyday public spaces and their implications for well-being and social relations. Health \& Place, 14(3):544 - 561, 2008.

[2] Tao Jiang. Urban public art and interaction design strategy based on digital technology. Cluster Computing, 0123456789:1-8, 2018.

[3] Camilo Salazar. What is sound art? https: //www.morleycollege.ac.uk/news/ 160-what-is-sound-art, 2019. [Online; accessed 29-May-2019].

[4] Aleksandar Matic, Venet Osmani, and Oscar MayoraIbarra. Analysis of social interactions through mobile phones. Mobile Networks and Applications, 17(6):808819, 2012.

[5] Trident Cloud Limited. Cloud recording sound to band. https://itunes.apple.com/us/app/ trackd-music-social-studio/id978196692, 2019. [Online; accessed in 26-April-2019].

[6] Rossi. Nathália Angela Fragoso and Barbosa. Rogério Vasconcelos. A música indeterminada de john cage: a relação compositor-intérprete. $\quad X X V$ Congresso da Associação Nacional de Pesquisa e Pós-Graduação em Música, 2015.

[7] Eloy Fernando Fritsch. Música Eletrônica-Uma Introdução Ilustrada. Eloy Fernando Fritsch, 2008.

[8] Davide Rocchesso, Stefania Serafin, Frauke Behrendt, Nicola Bernardini, Roberto Bresin, Gerhard Eckel, Karmen Franinovic, Thomas Hermann, Sandra Pauletto, Patrick Susini, and Yon Visell. Sonic interaction design: Sound, information and experience. In CHI '08 Extended Abstracts on Human Factors in Computing Systems, CHI EA '08, pages 3969-3972, New York, NY, USA, 2008. ACM.

[9] Thomas Hermann, Andy Hunt, and John G Neuhoff. The sonification handbook. Logos Verlag Berlin, 2011.

[10] Jorge Lopes Elen Nas. Design De Interfaces Para Experiências Lúdicas Com Novas Tecnologias: O Caso Do Software-Livre Reactivision Em Interações Sonoras. $12^{\circ}$ Congresso Brasileiro de Pesquisa e Desenvolvimento em Design, 2016.

[11] Pro Tools Cloud Collaboration. Link play together. https://www.avid.com/pro-tools/ cloud-collaboration, 2019. [Online; accessed in 26-April-2019].

[12] Siqueira. Denise da Costa Oliveira. Os jovens e suas telas pós-modernas: reflexões em torno da cidade, do imaginário e da tecnologia. Comunicação e Sociedade, 2010.

[13] B. Moore. An introduction to the psychology of hearing. 5 ed. Academic Press., 2003.

[14] M. Gerzon. Surround-sound psychoacoustics. Wireless World, p. 483-485, dez. 1974b., 1974.

[15] Denise Hortência Lopes Garcia. Modelos perceptivos na música eletroacústica. São Paulo, PUC [Doutorado em Comunicação e Semiótica], 1998.

[16] Regis Rossi A Faria, Leandro F Thomaz, Luciano Soares, Breno T Santos, Marcelo K Zuffo, and João Antônio Zuffo. Audience-audio immersion experiences in the caverna digital. In Proceedings of the10th Brazilian Symposium on Computer Music, Belo Horizonte, pages 106-117, 2005.

[17] El País Brasil. Android já é o sistema operacional mais usado do mundo. https://brasil.elpais. com/brasil/2017/04/04/tecnologia/ 1491296467_396232.html, 2019. [Online; accessed in 12-May-2019].

[18] Compomus. Media generated from study with compomus playstop and joystick. http: // compomus.wixsite. com/compomus, 2019. [Online; accessed 10-May-2019].

[19] LANDR. Free sample packs to inspire your next project. https://samples.landr.com/, 2019. [Online; accessed in 26-April-2019].

[20] Robert K Yin. Estudo de Caso: Planejamento e Métodos. Bookman editora, 2015.

[21] F. D. Davis, R. P. Bagozzi, and P. R. Warshaw. User acceptance of computer technology: a comparison of two theoretical models. Comunicação e Sociedade, 1989.

[22] Marlon Dalmoro and Kelmara Mendes Vieira. Dilemas na construção de escalas tipo likert: o número de itens e a disposição influenciam nos resultados? Revista gestão organizacional, 6(3), 2014. 